\title{
Dive efficiency versus depth in foraging emperor penguins
}

\author{
Ilka Zimmer ${ }^{1, *}$, Rory P. Wilson ${ }^{2}$, Michaël Beaulieu ${ }^{3}$, Yan Ropert-Coudert ${ }^{3}$, \\ Akiko Kato ${ }^{4}$, André Ancel ${ }^{3}$, Joachim Plötz ${ }^{1}$ \\ ${ }^{1}$ Alfred Wegener Institute for Polar and Marine Research, PO Box 120161, 27515 Bremerhaven, Germany \\ ${ }^{2}$ Institute of Environmental Sustainability, School of Biological Sciences, Swansea University, Singleton Park, \\ SA2 8PP Swansea, UK \\ ${ }^{3}$ IPHC_Département Écologie, Physiologie et Éthologie-UMR7178 Centre National de la Recherche Scientifique and \\ Université Louis Pasteur, 23 rue Becquerel, 67087 Strasbourg, France \\ ${ }^{4}$ National Institute of Polar Research, 1-9-10 Kaga, Itabashi, Tokyo 173-8515, Japan
}

\begin{abstract}
Dive duration generally decreases with dive depth in air-breathing vertebrates. In most penguin species, this occurs due to increasing transit (descent and ascent) durations. However, in U-shaped dives, this is also because the duration of the bottom phase of the dive increases with increasing depth. We considered the time-based efficiency with which birds can use different diving depths by using depth recorders on 9 foraging emperor penguins Aptenodytes forsteri, studied during the early and late chick-rearing period in Adélie Land, Antarctica. Dive and post-dive duration positively correlated with diving depth, but particularly long recovery durations were apparent for dives longer than $456 \mathrm{~s}$. This inflection point (i.e. $456 \mathrm{~s}$ ) corresponded to a theorized maximum rate of gain of prey per dive cycle. By using the number of undulations in the bottom phase of the dive as a proxy for prey capture success, we conclude that the most lucrative dive depths for the birds studied were between 50 and $225 \mathrm{~m}$. Since these depths were also those most often visited, we think that foraging emperor penguins focus on depths where profitability is highest.
\end{abstract}

KEY WORDS: Emperor penguins $\cdot$ Foraging depth $\cdot$ Bottom dive duration $\cdot$ Dive efficiency

\section{INTRODUCTION}

Much of the optimal foraging literature deals with how animals should behave to maximize their rate of energetic gain. The modulation of factors such as the time and energy involved in transiting between resting and foraging sites plays an important role in this (e.g. Shepard et al. 2009 and references therein). Penguins provisioning chicks are a good example of this: there is considerable selection pressure for them to organise the durations and depths underwater and the subsequent time spent recovering at the surface (Butler \& Jones 1997), so that they maximize the rate of energy acquisition (Weimerskirch 1998, Ropert-Coudert et al. 2004). This rate of energy acquisition is ultimately important in chick provisioning rates, and therefore brood survival (cf. Takahashi et al. 2003). The specific behaviour of a diving penguin (e.g. swim speed, rate of change of depth) determines the rate of oxygen use underwater (e.g. Kooyman \& Ponganis 1994) and subsequently when the bird is at the surface between dives (Kooyman \& Ponganis 1998). Both physiological processes affect the amount of time that can be spent at depth and consequently define the ultimate efficiency of the penguin for hunting prey at depth.

Emperor penguins Aptenodytes forsteri are the deepest diving birds, with a maximum recorded dive depth of $564 \mathrm{~m}$ (Wienecke et al. 2007). This diving ability allows them to prey on squid and fish at great depths in the Southern Ocean where no other avian species can compete (Ropert-Coudert et al. 2006a). Deeper dives, however, require longer (and energeti- 
cally more costly) transit phases to depth and may then require longer surface recovery time (e.g. Kooyman \& Ponganis 1998) and result in poorer diving efficiency (Wilson 2003). Such a reduced diving efficiency might be compensated, however, by appropriately greater gains in prey acquisition rates at those depths.

We examined the foraging behaviour of breeding emperor penguins. We analysed the depths at which these birds operated, assessed how diving efficiency varied according to foraging depth, and considered whether our depth-dependent, derived efficiencies correlated with putative prey ingestion rates and whether the birds maximized rate of prey ingestion versus time.

\section{MATERIALS AND METHODS}

Study site and data records. We conducted fieldwork at the emperor penguin colony at Pointe Géologie, Adélie Land, Antarctica ( $66^{\circ} 40^{\prime} \mathrm{S}, 140^{\circ} 01^{\prime} \mathrm{E}$ ) during the 2005 breeding season, between 20 April and 31 August in winter and 2 and 21 November in spring.

We attached time-depth recorders (Mk9, Wildlife Computers, $6.7 \times 1.7 \times 1.7 \mathrm{~cm}, 30 \mathrm{~g}$ ) to 3 female and 2 male penguins between 20 April and 11 May, in the pairing period. We glued the instruments to the bird's feathers on the midline of the lower back to minimize drag (Bannasch et al. 1994).

Between 2 and 13 November in the late chick rearing period, a further 4 adult penguins were captured travelling to or from the colony (when the colony to sea distance was about $500 \mathrm{~m}$ ). The sex of the birds is difficult to determine during this period. Consequently we inferred sex for one female and one male by their vocalisations (Robisson 1992). We attached a satellitelinked, data-collecting tag (Splash, Wildlife Computers, $7.8 \times 5.0 \times 2.3 \mathrm{~cm}, 105 \mathrm{~g}$ ) with black Tesa-tape (Wilson et al. 1997b) on the lower back feathers of the penguins.

The Mk9 archival tag had a relative depth resolution of $0.5 \mathrm{~m}$, a memory of $16 \mathrm{MB}$ and was set to record depth every $5 \mathrm{~s}$. The Splash tag had a relative depth resolution of $0.1 \mathrm{~m}$, a $14 \mathrm{MB}$ memory, and was set to record depth every $2 \mathrm{~s}$. Both devices recorded within the range of 0 to $1000 \mathrm{~m}$ depth.

Data analysis. We analysed dive depth data (corrected for surface drift which varied by $\pm 2 \mathrm{~m}$ ) using MT-dive, software specially developed for this purpose (Jensen Software). The software analysed dives sequentially, writing a number of defining parameters for each dive into an ASCII output file. These were: the time of the dive initiation; the overall dive duration; the maximum depth reached during the dive; the descent-, bottom-, and ascent-phase durations; the vertical velocities during the descent, bottom and ascent phases; the number of rapid succession short ascent/descent phases during the bottom phase; and the post-dive interval (Fig. 1).

We considered dives deeper than $2 \mathrm{~m}$ as proper dives for further dive analysis. We defined the bottom phase of each dive, during which penguins are most

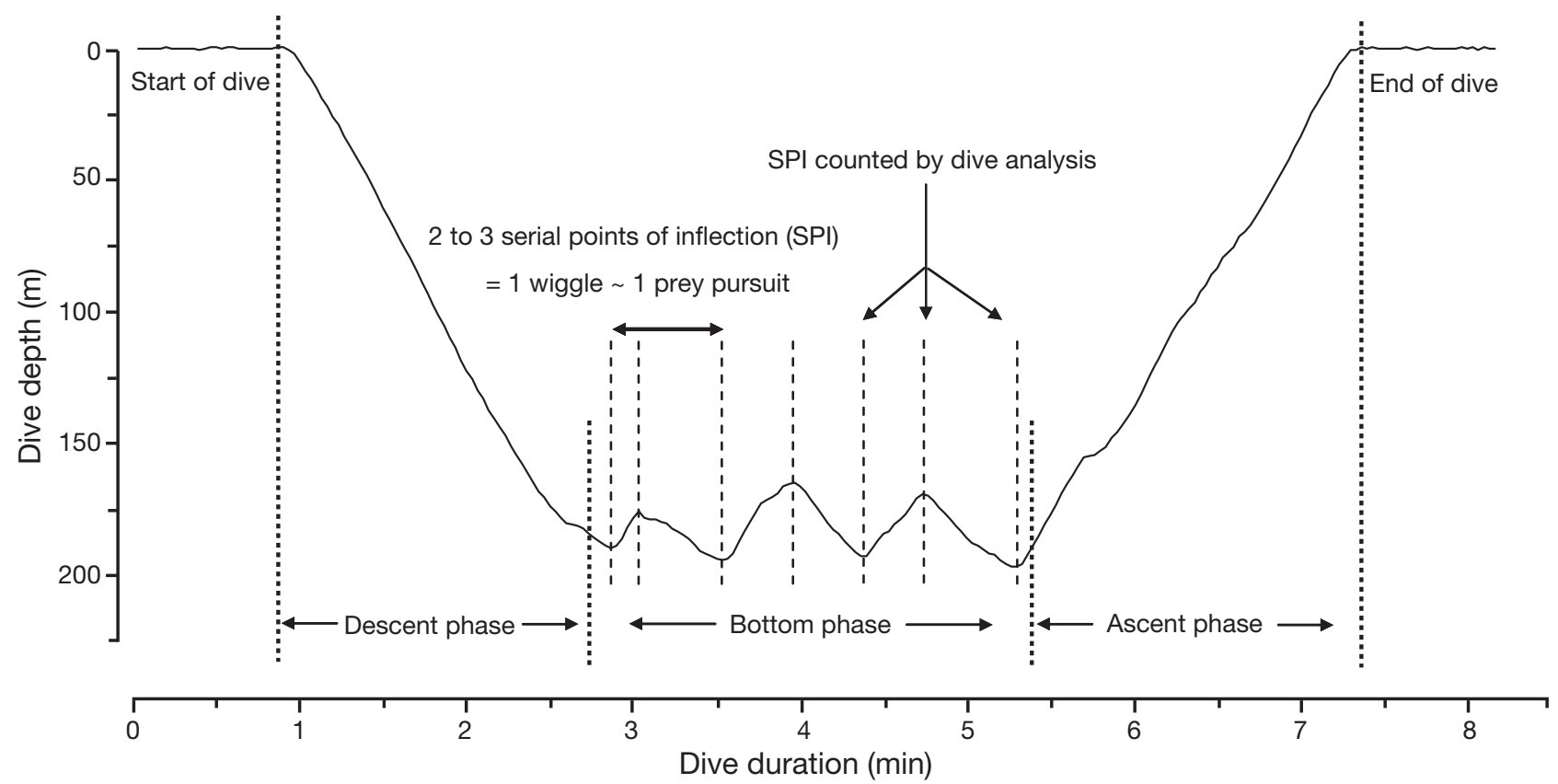

Fig. 1. Aptenodytes forsteri. Example of a dive classified into descent, bottom and ascent phase. A wiggle during the bottom phase is defined by 2 to 3 registered serial points of inflection (SPI) counted during dive analysis 
likely to hunt (e.g. Wilson et al. 1995) and appear to capture most of their prey (e.g. Simeone \& Wilson 2003, Ropert-Coudert et al. 2006b), by 3 conditions: it could only occur (1) at depths $>85 \%$ of the maximum depth of the dive (dive analysis package DA, Wildlife Computers); (2) if it was bounded by 2 points of inflection in the rate of change of depth (indicating the start and end of a clear bottom period); and (3) if the overall rate of change of depth for the whole of the putative bottom period did not exceed $0.2 \mathrm{~m} \mathrm{~s}^{-1}$ (Rodary et al. 2000a). Short ascent and descent phases that exceeded $2 \mathrm{~m}$ during the bottom phase of a dive were quantified according to the number of points of inflection during the ascents and descents (Fig. 1). We described 2 or 3 serial points of inflection (SPI) as a 'wiggle'. Single wiggles of this type reported for Magellanic penguins Spheniscus magellanicus have been shown, overall, to result in the capture of a single prey item during the bottom phases of their dives (Simeone \& Wilson 2003). Moreover, wiggles are generally considered to be indicative of prey pursuit in penguins (e.g. Kirkwood \& Robertson 1997, Rodary et al. 2000b). Consequently, we considered the number of wiggles occurring in the bottom phase of emperor penguin dives to be linearly related to prey abundance in that they represented a pursuit with, or without, prey capture. We note that the validity of this assumption is critical to our assessment of 'catch per unit effort'. Our estimate of prey abundance via 'catch per unit effort' (CPUE, SPI $\mathrm{min}^{-1}$ ) statistics was obtained by dividing the number of serial points of inflection during the bottom phase by the bottom dive duration. Likewise, the diving efficiency (DE) was calculated following the equation of Ydenberg \& Clark (1989):

$$
\begin{aligned}
& \mathrm{DE}=\text { bottom duration/ } \\
& \text { (dive duration + post-dive duration) }
\end{aligned}
$$

being expressed as a non-dimensional fraction. As an overall measure for DE and CPUE, the product of these parameters was calculated as the CPUE $\times$ DE index, being expressed as SPI $\mathrm{min}^{-1}$.

We analysed dive data for each data set. The 2 different study periods of winter and spring in the breeding cycle of emperor penguins resulted in different foraging trip characteristics (e.g. trip direction and range, trip duration and, thus, the overall number of dives conducted; see Zimmer et al. 2007). We log-transformed results of the dive parameters (e.g. as dive durations, dive efficiency and the CPUE, being variables that change with depth) in order to satisfy normality rules before being investigated using General Linear Models with bird as the random factor. For clarity, the data are presented as grand means $\pm 1 \mathrm{SE}$ and averaged per $25 \mathrm{~m}$ maximum dive depth interval. We calculated all parameters for dives with post-dive durations of less than 25 min (as delineated by a point of inflection in the frequency of postdive duration graph; cf. bout-ending criterion Gentry \& Kooyman 1986). We processed data using Origin 7.5, TableCurve 2D and JMP 6.0, SAS 2005.

\section{RESULTS}

We analysed dive records of 9 emperor penguins, consisting of one complete foraging trip for each. We also analysed dives of a second foraging trip for one of the females in winter. Those trips provided $277 \mathrm{~d}$ of foraging time at sea and 24403 dives. The maximum dive depth was $438 \mathrm{~m}$ (mean: $68.83 \mathrm{~m} \pm 0.52$, median: $32.76 \mathrm{~m}$, range: $2.00-438.37 \mathrm{~m})$. The maximum dive duration was 16 min (mean: $3.00 \mathrm{~min} \pm 0.02$, median: $2.67 \mathrm{~min}$, range: $0.10-16.08 \mathrm{~min}$ ).

We examined dive duration and post-dive duration for all dives that had post-dive intervals $<25$ min $(\mathrm{n}=$ 24068 dives). Both parameters were positively correlated with maximum dive depth (log dive duration: $\mathrm{r}^{2}=0.88, F_{1,24063}=165011.4, \mathrm{p}<0.001$ [Fig. 2a] and $\log$ post-dive duration: $\mathrm{r}^{2}=0.40, F_{1,24063}=13551, \mathrm{p}<0.001$ [Fig. 2b]) and there were no significant differences between seasons (log dive duration: $F_{2,6}=1.59, \mathrm{p}=0.28$, and $\log$ post-dive duration: $F_{2,6}=2.48, \mathrm{p}=0.16$ ).

The rate of increase of the post-dive duration was higher for deep dives between 225 to $450 \mathrm{~m}$, being $1.7 \mathrm{~s} \mathrm{~m}^{-1}$, than for shallower dives between 0 to $225 \mathrm{~m}$, being $0.35 \mathrm{~s} \mathrm{~m}^{-1}$ (Fig. 2b). Log-transformed post dive duration and dive duration were positively correlated $\left(\mathrm{r}^{2}=0.37, F_{1,24062}=11759.6, \mathrm{p}<0.001\right.$ [Fig. 3a] $)$ and not different between seasons $\left(F_{2,6}=3.31, \mathrm{p}=0.11\right)$.

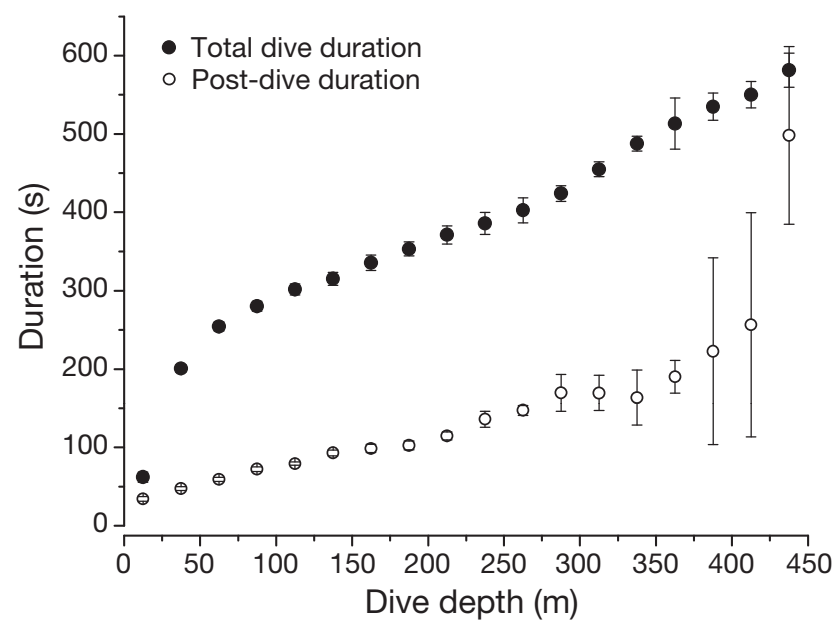

Fig. 2. Aptenodytes forsteri. Dive and post-dive duration as function of maximum dive depth for dives with post-dive durations $<25 \mathrm{~min}_{\text {; }} \mathrm{n}=24068$ dives; $\mathrm{n}=9$ penguins. Values are grand means $\pm 1 \mathrm{SE}$ 


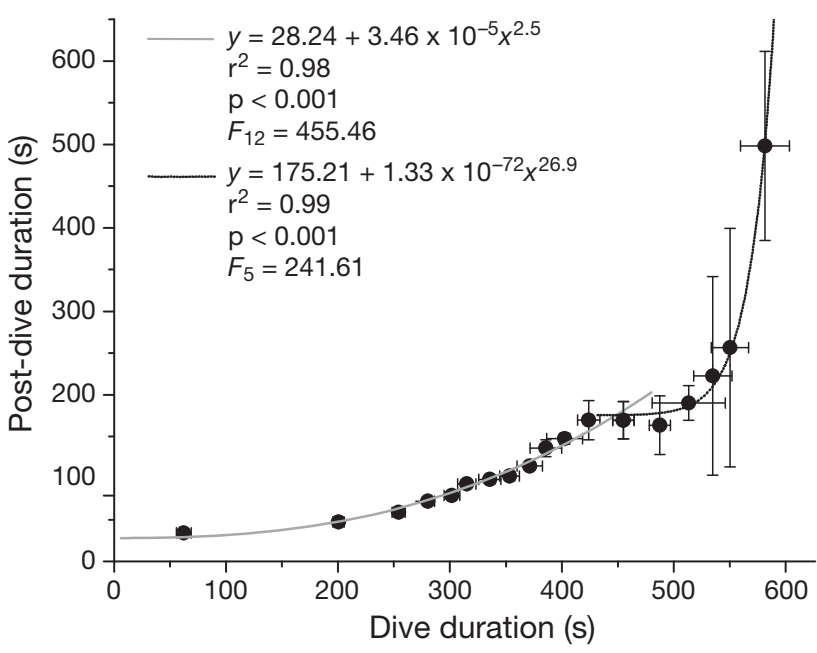

Fig. 3. Aptenodytes forsteri. Post-dive duration as function of dive duration for dives with post-dive durations $<25 \mathrm{~min}^{\mathrm{n}} \mathrm{n}=$ 24068 dives, $\mathrm{n}=9$ penguins. This relation is described by two different correlations due to a point of inflection at $455 \pm 9 \mathrm{~s}$, causing a change of the slope. Values are grand means $\pm 1 \mathrm{SE}$

We visually determined a point of inflection at $456 \pm$ $9 \mathrm{~s}$ from plots of dive duration in relation to post-dive duration (Fig. 3a) and tested the relationship separately before and after this same point of inflection. For the shorter log dive durations (dives <456 s) the log post-dive duration was positively correlated $\left(\mathrm{r}^{2}=0.36\right.$, $\left.F_{1,23389}=11189, \mathrm{p}<0.001\right)$ and did not differ between seasons $\left(F_{2,6}=2.59, \mathrm{p}=0.15\right.$ [Fig. 3b]). For the longer log dive durations (of dives $>456$ s) the log post-dive duration was also positively correlated but with a higher rate of change with depth $\left(\mathrm{r}^{2}=0.16, F_{1,663}=\right.$ 18.7, $\mathrm{p}<0.001)$ while, similarly, not differing between seasons $\left(F_{2,5}=3.08, \mathrm{p}=0.13\right.$ [Fig. 3c]).

Duration of descent and ascent was positively correlated to maximum depth $\left(\mathrm{r}^{2}=0.85, F_{1,24063}=130625\right.$, $\mathrm{p}<0.001$ [Fig. 4a] and $\mathrm{r}^{2}=0.84, F_{1,24063}=116114, \mathrm{p}<$ 0.001 [Fig. 4c]) and not different between seasons $\left(F_{2,6}=0.035, \mathrm{p}=0.97\right.$ and $\left.F_{2,6}=1.24, \mathrm{p}=0.35\right)$.

Eighty percent of 24068 dives (with post-dive intervals $<25$ min; $\mathrm{n}=19248$ dives) had a bottom phase. Bottom duration was shorter than descent and ascent during dives and accounted for $30 \pm 0.4 \%$ of the dive duration on average overall. Bottom duration increased with increasing maximum dive depth for dives $<225 \mathrm{~m}\left(\mathrm{r}^{2}=0.61, F_{1,17621}=26134, \mathrm{p}<0.001\right.$ [Fig. 4b]) and was not different between seasons $\left(F_{2,6}=2.12, \mathrm{p}=\right.$ $0.20)$, but then decreased with dives $>225 \mathrm{~m}\left(\mathrm{r}^{2}=0.14\right.$, $F_{1,1576}=49.5, \mathrm{p}<0.001$ [Fig. 4b]), again without seasonal difference $\left(F_{2,2}=1.20, \mathrm{p}=0.45\right)$.

Dives with serial points of inflection (SPI dives, $\mathrm{n}=$ 13915), which suggest prey pursuit movements, occurred in $72 \%$ of dives with a bottom phase. The frequency distribution of all dives with SPIs showed 2
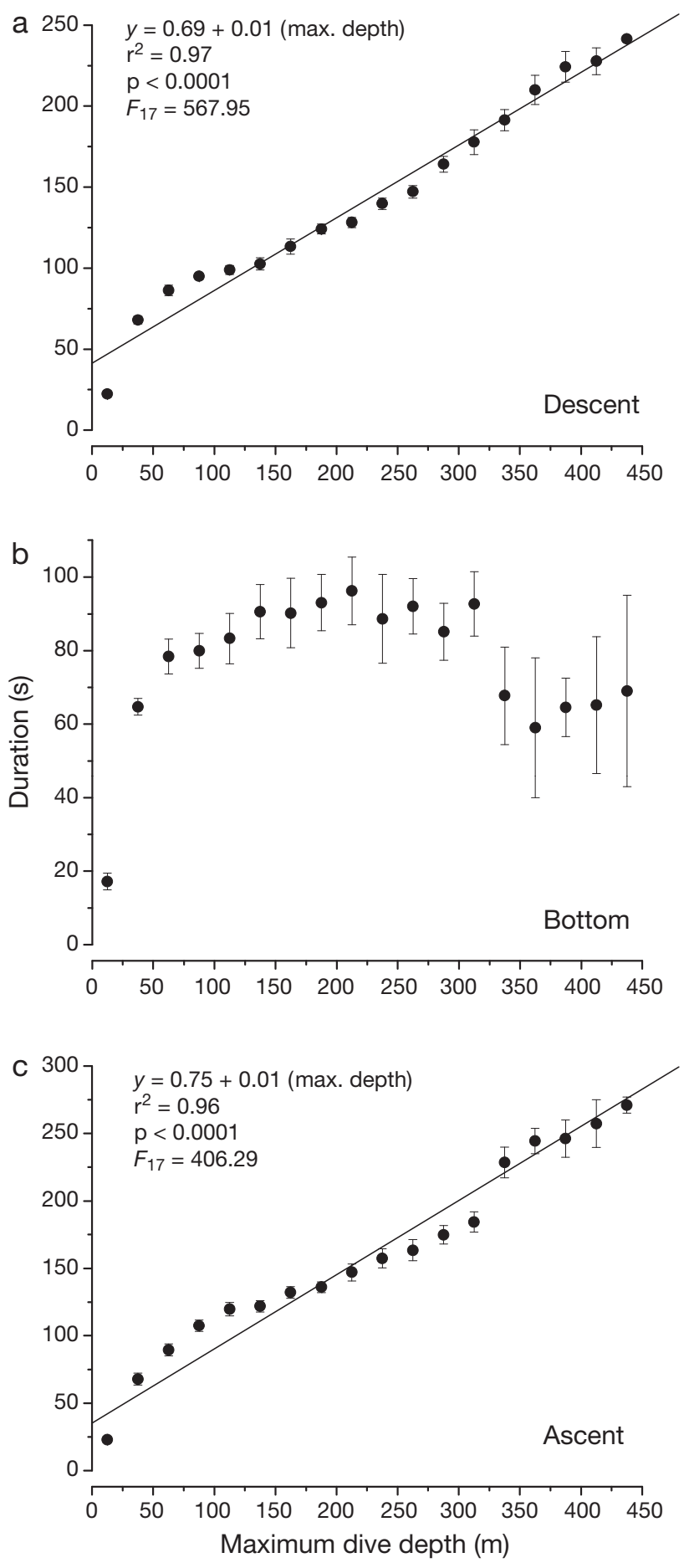

Fig. 4. Aptenodytes forsteri. Durations of (a) descent, (b) bottom, and (c) ascent phases of dives as function of maximum dive depth for dives with post-dive durations $<25$ min; $\mathrm{n}=$ 24068 dives, $\mathrm{n}=9$ penguins. Values are grand means $\pm 1 \mathrm{SE}$

apparent peaks, one for dives with maximum depths between 25 and $75 \mathrm{~m}$ ( $23 \%$ of dives) and another for dives with maximum depths between 125 and $225 \mathrm{~m}$ ( $41 \%$ of dives, Fig. 5a). 

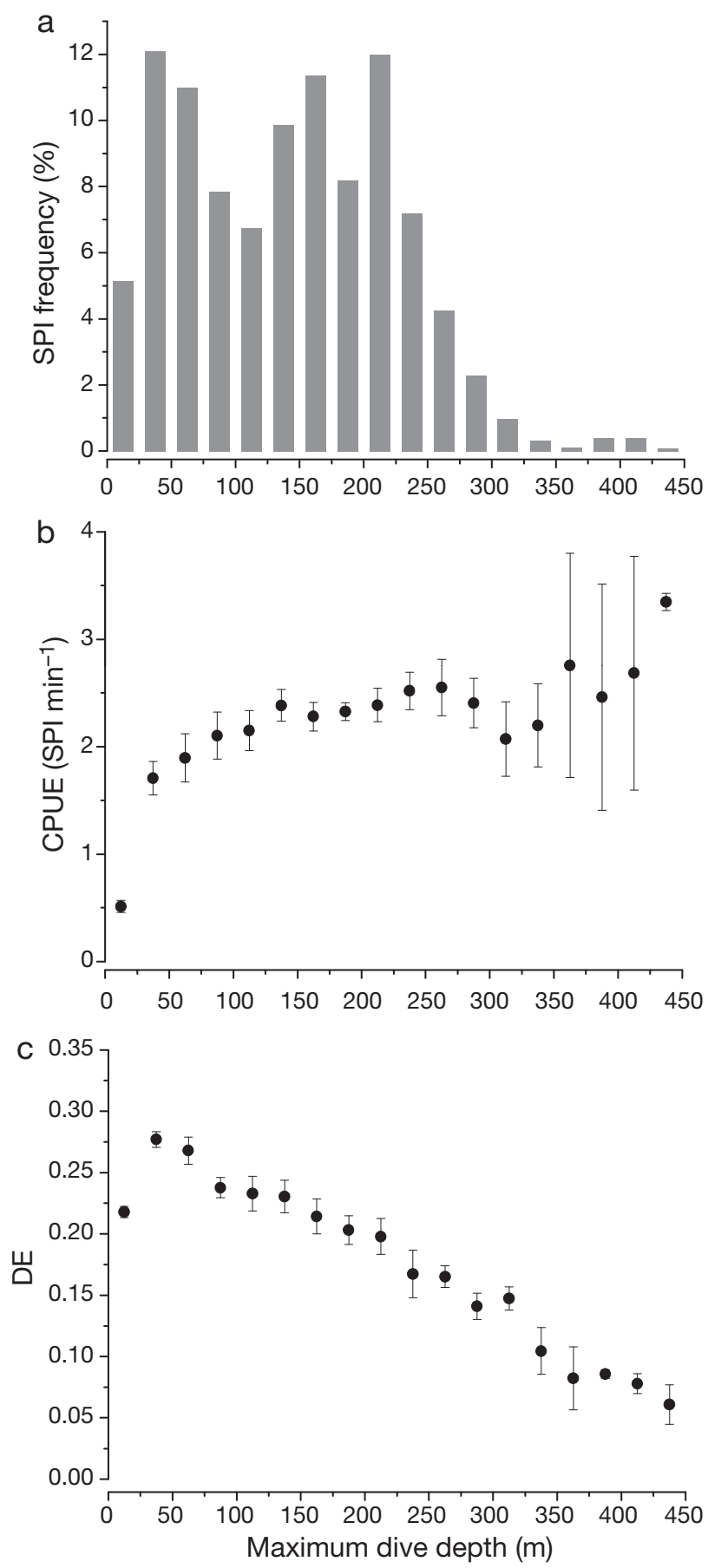

Fig. 5. Aptenodytes forsteri. (a) Serial point of inflection (SPI) frequency in percent, (b) catch per unit effort (CPUE, SPI $\mathrm{min}^{-1}$ ), and (c) dive efficiency (DE) as a function of maximum dive depth for dives with post-dive durations $<25 \mathrm{~min}$ and a bottom phase; $\mathrm{n}=19248$ dives, $\mathrm{n}=9$ penguins. Values are grand means $\pm 1 \mathrm{SE}$

Although the catch per unit effort (CPUE) appeared relatively constant in dives to depths between 50 and $450 \mathrm{~m}$ (Fig. 5b), it actually increased significantly with depth $\left(\mathrm{r}^{2}=0.061, F_{1,13788}=98.1, \mathrm{p}<0.001\right)$. The rela-

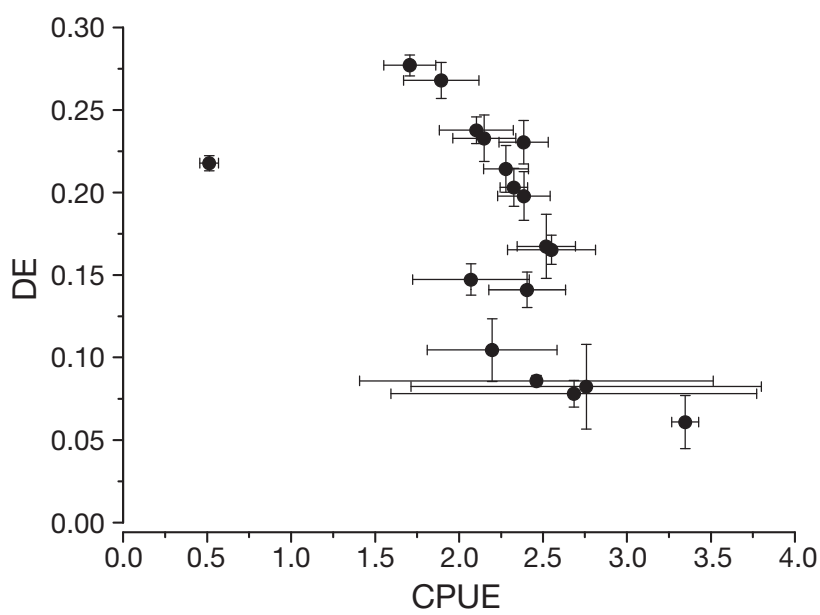

Fig. 6. Aptenodytes forsteri. Dive efficiency (DE) as function of catch per unit effort (CPUE, SPI $\mathrm{min}^{-1}$ ) for dives with postdive durations $<25 \mathrm{~min}$ and bottom phase; $\mathrm{n}=19248$ dives, ( $\mathrm{n}=9$ penguins). Values are grand means $\pm 1 \mathrm{SE}$

tionship was different between seasons $\left(F_{2,6}=9.17, \mathrm{p}=\right.$ 0.016).

The dive efficiency (DE) only increased with maximum depth for dives up to $50 \mathrm{~m}$ before decreasing substantially with increasing dive depth $\left(\mathrm{r}^{2}=0.011\right.$, $F_{1,19239}=55.0, \mathrm{p}<0.001$ ) to a minimum mean value of $0.06 \pm 0.02$ for dives terminating between 425 to $450 \mathrm{~m}$ (Fig. 5c). There was no difference between seasons $\left(F_{2,6}=0.39, \mathrm{p}=0.70\right)$.

Dive efficiency was negatively correlated with the CPUE $\left(\mathrm{r}^{2}=0.044, F_{1,13790}=771, \mathrm{p}<0.001\right.$ [Fig. 6]) without difference between seasons $\left(F_{2,6}=0.55, \mathrm{p}=0.60\right)$.

The overall measure for diving efficiency and the effort of catching prey, the CPUE $\times$ DE index, increased with the maximum dive depth remaining high until $225 \mathrm{~m}$, but then decreased with deeper dives $\left(\mathrm{r}^{2}=\right.$ 0.087, $F_{1,13786}=587, \mathrm{p}<0.001$ [Fig. 7]) and was not different between seasons $\left(F_{2,6}=5.41, \mathrm{p}=0.046\right)$. Highest values for this occurred between 125 to $150 \mathrm{~m}$ with the overall relationship being negative.

\section{DISCUSSION}

We combined data from males and females for different seasons. The seasonal and inter-sex variation of diving behaviour of emperor penguins in Dumont d'Urville has been reported and discussed elsewhere (Zimmer et al. 2007). The extent to which these variations affect the validity of our conclusions is difficult to evaluate but we think this is important to consider. We assume, however, that the overall trends in diving behaviour (e.g. descent and ascent duration) with respect to depth are similarly affected by season and sex, as they are determined by physical diving proper- 


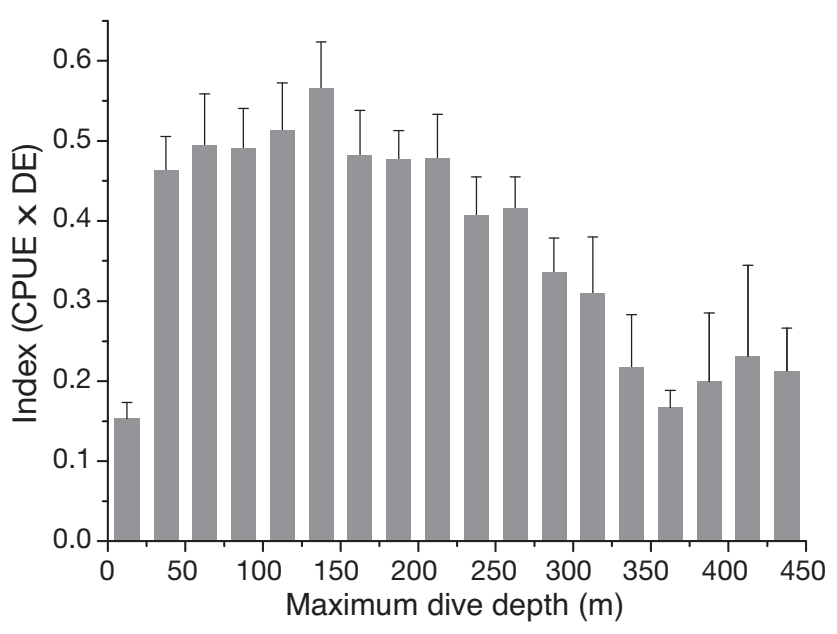

Fig. 7. Aptenodytes forsteri. Frequency of the catch per unit effort $\times$ dive efficiency $\left(\right.$ CPUE $\times$ DE) index $\left(\right.$ SPI $\left.\mathrm{min}^{-1}\right)$ as function of maximum dive depth for dives with post-dive durations $<25$ min and bottom phase; $\mathrm{n}=19248$ dives, $\mathrm{n}=9$ penguins. Error bars: $\pm 1 \mathrm{SE}$

ties of the diving bird (e.g. air-mediated up thrust with respect to depth etc.). This assumption was supported by our statistical findings. Variation in environmental parameters (such as prey density with depth) might be expected to change with season and this may explain the seasonal differences in CPUE that we detected.

Increases in dive duration with depth identified in our study have been previously reported for emperor penguins (e.g. Kooyman \& Kooyman 1995, Kirkwood \& Robertson 1997), and are similar to those reported for a variety of diving endotherms (e.g. Schreer et al. 2001). There are 2 apparent reasons for this. First, travel to greater depths from the surface generally occurs at roughly constant swim speeds (RopertCoudert et al. 2001, Wilson et al. 2002) that are close to the minimum costs of transport (cf. Culik et al. 1994). The rate of change of depth in those cases is modulated by dive angle, which itself, is related to the maximum dive depth. Consequently, deeper dives have longer transit durations. This applies to both the descent and the ascent and is a pattern that is particularly obvious in the dive patterns of the penguins we studied. Second, penguins evidently control the volume of air that they inhale prior to a dive so that they encounter conditions approaching neutral buoyancy during the extended bottom phase of their dives (Wilson \& Zimmer 2004). A consequence of this is that penguins swimming near the surface inspire less in their final breath which results in less oxygen in their respiratory air-spaces and reduces their capacity to stay underwater as long as birds that dive deeper (Wilson \& Zimmer 2004).
Although time taken to descend and ascend the water column is roughly a linear function of depth (Fig. 4), there is a marked increase in duration (which signals particularly slow rates of ascent) for dives deeper than $325 \mathrm{~m}$. Penguins might slow their rate of ascent to mitigate the bends (Sato et al. 2003). We found that rate of ascent slowed for the deepest dives and we think this supports that hypothesis.

A major, non-linear factor that evidently modulates the length of the dive cycle (and therefore the efficiency of dives with respect to depth) is the time spent at the surface to recover from the previous dive(s) when any oxygen deficit is corrected in preparation for the next dive. Generally, the rate at which oxygen is taken up by a body is considered to be proportional to the difference in partial pressure between the body tissues and the air (Kramer 1988). Thus, birds with a high oxygen deficit acquire oxygen fast. It is specifically the process of loading the oxygen to high levels (as well as eliminating $\mathrm{CO}_{2}$, Boutilier et al. 2001) that is so time consuming at the surface, making surface durations exceptionally long following long, deep dives. Moreover, long dives require high pre-dive oxygen partial pressures in the tissues. Exceptionally long dive durations may also involve anaerobic metabolism (Kooyman \& Ponganis 1998) and consequently require even longer recovery periods to process the accumulated lactate (e.g. Ponganis et al. 1997).

However, it is the bottom phase that appears to be the most important factor for determining the real value of the dive since that is when and where the penguins acquire prey (Simeone \& Wilson 2003, RopertCoudert et al. 2006b). It is a major factor regulating the time spent underwater in relation to depth and it is advantageous for the birds to maximize this time in relation to all other phases of the dive cycle (Wilson et al. 1996). We observed an initial increase in bottom duration with increasing depth until maximum depths of $225 \mathrm{~m}$ were reached. That corresponded to total dive duration of about 6 min, after which bottom duration declined with further increases in maximum dive depth. Charrassin et al. (2002) did not observe this for king penguins Aptenodytes patagonicus, but birds might not have hunted at depths great enough for body oxygen reserves to be used substantially for transit. The decrease in bottom duration that we observed for deeper dives might indicate that birds were approaching the limits of their total body oxygen stores during those dives (cf. Butler \& Jones 1997). In that event increases in dive depth beyond a threshold and the correlated increases in descent and ascent durations (see above), should result in a corresponding reduction in bottom phase duration. This should only strictly be true, however, if overall dive duration plateaus at the time the bottom duration starts to 
decrease. This is clearly not the case in emperor penguins (Figs. 2a \& 4b).

To understand why bottom duration varied with depth in our study we used our descriptors of dive behaviour together with measures of foraging efficiency proposed by other workers in the field and then varied bottom duration to see how it might theoretically affect foraging success. Simplistically though, given that most prey is caught during the bottom phase of the dive, increases in dive depth (and therefore transit duration) should correlate with increases in bottom duration if birds are to remain efficient (assuming constant rates of prey ingestion for any fixed prey density irrespective of depth) that could explain why bottom duration might increase with increasing maximum dive depth. The subsequent decrease in bottom duration however is more complex. If, following Ydenberg (1988), the efficiency of a bird is taken to be:

Efficiency $=$ Bottom duration/

(Descent + Bottom + Ascent + Recovery duration $)$

and the prey encounter rate taken to be $\alpha$ per second spent in the bottom phase, then the overall rate of prey gain is given by:

Rate $=($ Bottom duration $\times \alpha) /$

(Descent + Bottom + Ascent + Recovery duration)

The effect of various bottom durations on the rate of prey acquisition as a function of depth can be examined by putting these bottom duration values into Eq. (3), substituting values for the durations of the descent and ascent to specific depths derived from our results (Fig. 4a,c) as well as equations relating the recovery duration to dive duration (Fig. 3b,c). This approach shows that longer bottom durations would be most profitable at shallower depths (Fig. 8a) primarily due to the observed accelerating surface recovery duration with increasing overall dive duration (Fig. 3). Indeed, the form of the rate of gain as a function of bottom duration for dives to different maximum depths is shown in Fig. 8b, which makes clear how the maximum rate of gain per dive cycle occurs at shorter bottom durations for the greater depths. This helps explain the downward trend in bottom duration observed in our data for dives deeper than $225 \mathrm{~m}$.

Though this might be a mechanistic basis for the relationship between bottom phase depths, it is the abundance of prey as a function of depth that will ultimately determine the profitability of dives. We would not expect prey abundance to be constant with depth and this might explain the differences between predicted and actual bottom durations versus depth. Dives to depths that result in low efficiency should only be tenable if they can be balanced by an enhanced rate of prey ingestion. Thus, the inverse of the dive efficiency
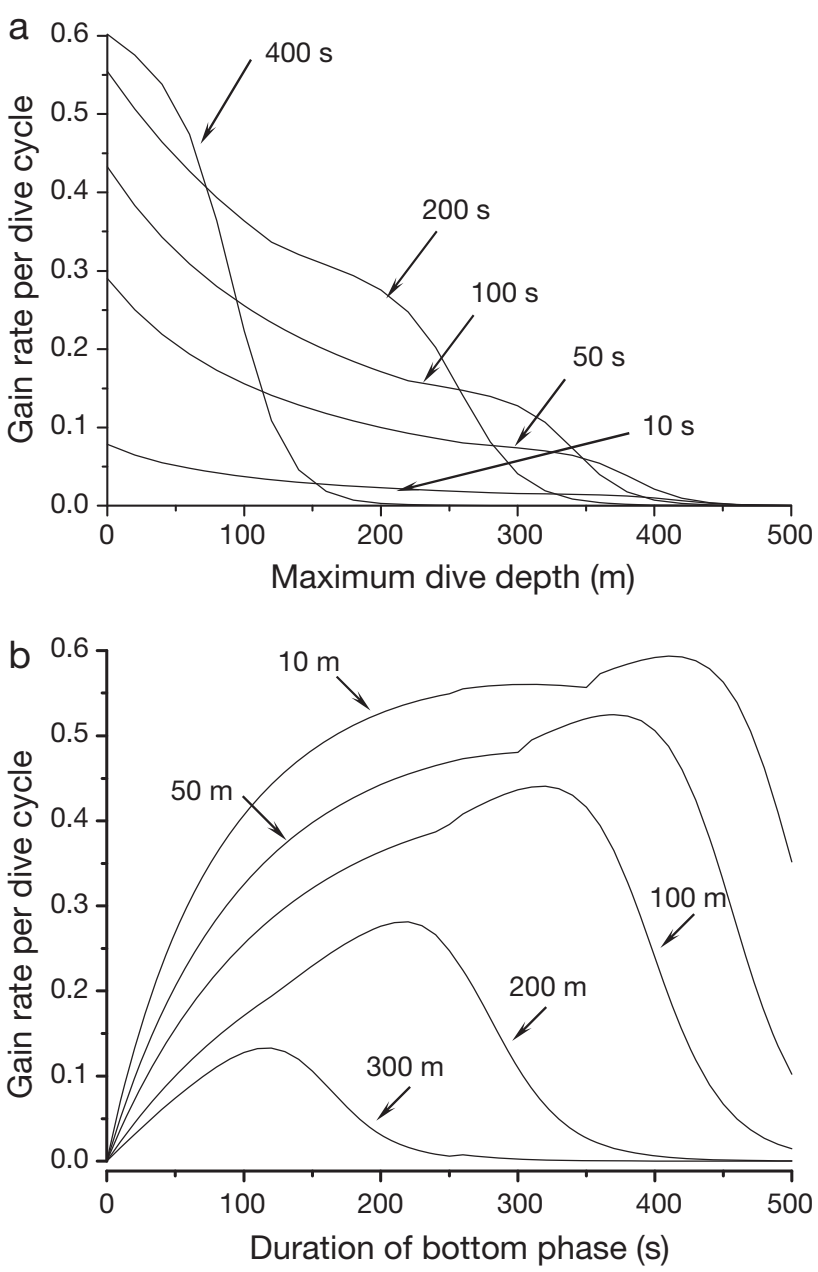

Fig. 8. Aptenodytes forsteri. Theoretical rate of gain of prey (assuming a constant rate of ingestion per unit time during the bottom phase of the dive), calculated over the whole dive cycle, as a function of (a) dive depth for different fixed bottom durations (s), and (b) as a function of bottom duration for different fixed maximum dive depths $(\mathrm{m})$. Overall rate of prey ingestion is calculated for particular conditions of bottom duration and depth by using known regressions for descent and ascent durations to that depth (Fig. $4 \mathrm{a}, \mathrm{c}$ ) and determining the total surface recovery duration necessary after the bottom duration has been added to these (cf. Fig. 3b,c)

should theoretically give a measure of the rate of prey ingestion needed to make dives profitable. The significant relationship between dive efficiency and CPUE (Fig. 6) (assuming that wiggles can be used as a measure of prey pursuit) suggests that emperor penguins only hunt prey at greater depths when prey density is high there. We stress though that we do not know how the SPI's relate to real prey capture success as a function of depth. In addition, the CPUE $\times$ DE index, which is a measure for how lucrative different depths were for studied birds, shows that the overall gain per unit time was greatest over a broad depth range between 
about 25 and $225 \mathrm{~m}$. The low values at $<25 \mathrm{~m}$ may simply reflect the disadvantageous energetics of having to swim near the surface due to higher buoyancy (cf. Sato et al. 2003) and also that birds moving to and from foraging areas swim close to the surface to travel (cf. Wilson \& Wilson 1995). Beyond $225 \mathrm{~m}$ the CPUE $\times \mathrm{DE}$ index dropped, even though there appeared to be a slight rise after $350 \mathrm{~m}$ dive depth. This agrees generally the frequency of depth maxima where the birds foraged, further suggesting that emperor penguins focus foraging effort at depths where overall gain is greatest. This tactic is consistent with maximising gain while foraging.

Predicted trends might be confounded, however, by dives where prey are not encountered because it is not clear what birds do to modulate their bottom duration during these dives, though they return directly to the surface without any extension of the bottom phase at all during $20 \%$ of the time. Presumably foraging birds decide whether to hunt prey at any particular depth relative to perceived prey density (cf. Krebs et al. 1974). Given the fairly strict form of the dive profile, consisting of a clear, single descent phase followed by equally clear bottom and finally ascent phases in emperor penguins (e.g. Robertson 1995), king penguins (e.g. Kooyman et al. 1992), chinstrap penguins Pygoscelis antarctica (Wilson \& Peters 1999), Adélie penguins Pygoscelis adeliae (Rodary et al. 2000b), rockhopper penguins Eudptes chryscome (Wilson et al. 1997a), Gentoo penguins Pygoscelis papua (Wilson et al. 1996), and Spheniscus spp. (Peters et al. 1998), it appears that these birds make a single decision relating to appropriate bottom depth for each dive. There are never 2 distinct bottom depths where the birds' foraged during any single dive. This apparent inflexibility may, in part, be related to buoyancy problems. Other species of penguins (king, Adélie and Magellanic) inhale air before diving relative to the bottom depth of the next dive (Wilson \& Zimmer 2004). We think this might be to allow them to operate during the bottom phase at virtually neutral buoyancy and thus reduce swim costs (Wilson \& Zimmer 2004) and extend the dive duration. While this approach is energetically sensible, it constrains birds to operate at particular depths that are chosen before the dive is initiated. Indeed, departures from the optimum foraging depth must be particularly energetically rewarding for them to be tenable. Variance in use of depth by foraging penguins is primarily based, therefore, on changes in maximum depth between dives (Wilson et al. 1996). We would expect the depth used during dive $\mathrm{N}$ to depend strongly on the type and density of prey encountered during dive N-1 (cf. Wilson 2003). Therefore we think that it is important to examine sequenced maximum dive depths (Wilson \& Peters 1999) in rela- tion to foraging success as a next step in understanding the foraging tactics of these birds that have to make judicious decisions about allocating time to acquire energy at a place distinct from where they acquire oxygen.

Acknowledgements. We thank the members of the 54th and 55th mission in Dumont d'Urville, and in particular our colleagues T. Raclot and A. Dervaux for their help in the field. Fieldwork was logistically supported by the Institut Polaire Français Paul-Émile Victor (IPEV) and the Terres Australes and Antarctiques Françaises (TAAF). This study was approved by the Ethics Committee of the French Polar Institute. Primary data are archived in the 'Publishing Network for Geoscientific \& Environmental Data' (PANGAEA) and are available in open access via doi.pangaea.de/10.1594/PANGAEA.633713.

\section{LITERATURE CITED}

Bannasch R, Wilson RP, Culik B (1994) Hydrodynamic aspects of design and attachment of a back-mounted device in penguins. J Exp Biol 194:83-96

Boutilier RG, Reed JZ, Fedak MA (2001) Unsteady-state gas exchange and storage in diving marine mammals: the harbor porpoise and gray seal. Am J Physiol 281:R490-R494

Butler PJ, Jones DR (1997) Physiology of diving of birds and mammals. Physiol Rev 77:837-899

Charrassin JB, Le Maho Y, Bost CA (2002) Seasonal changes in the diving parameters of king penguins (Aptenodytes patagonicus). Mar Biol 141:581-589

Culik B, Wilson R, Bannasch R (1994) Underwater swimming at low energetic cost by Pygoscelid penguins. J Exp Biol 197:65-78

Gentry RL, Kooyman GL (1986) Methods of dive analysis. In: Gentry RL, Kooyman GL (eds) Fur seals: maternal strategies on land and at sea. Princeton University Press, New Jersey, p 28-40

Kirkwood R, Robertson GG (1997) The foraging ecology of female emperor penguins in winter. Ecol Monogr 67: 155-176

Kooyman GL, Kooyman TG (1995) Diving behavior of emperor penguins nurturing chicks at Coulman Island, Antarctica. Condor 97:536-549

Kooyman GL, Ponganis PJ (1994) Emperor penguin oxygenconsumption, heart-rate and plasma lactate levels during graded swimming exercise. J Exp Biol 195:199-209

> Kooyman GL, Ponganis PJ (1998) The physiological basis of diving to depth: birds and mammals. Annu Rev Physiol 60:19-32

- Kooyman GL, Cherel Y, Le Maho Y, Croxall JP, Thorson PH, Ridoux V (1992) Diving behavior and energetics during foraging cycles in king penguins. Ecol Monogr 62: 143-163

Kramer DL (1988) The behavioral ecology of air breathing by aquatic animals. Can J Zool 66:89-94

> Krebs JR, Ryan JC, Charnov EL (1974) Hunting by expectation or optimal foraging:a study of patch use by chickadees. Anim Behav 22:953-964

> Peters G, Wilson RP, Scolaro JA, Laurenti S, Upton J, Galleli H (1998) The diving behavior of Magellanic penguins at Punta Norte, Península Valdès, Argentina. Colon Waterbirds 21:1-10 
Ponganis PJ, Kooyman GL, Starke LN, Kooyman CA, Kooyman TG (1997) Post-dive blood lactate concentrations in emperor penguins, Aptenodytes forsteri. J Exp Biol 200: 1623-1626

Robertson GG (1995) The foraging ecology of emperor penguins (Aptenodytes forsteri) at two Mawson coast colonies, Antarctica. ANARE Reports 138. Australian Antarctic Division, Kingston

Robisson P (1992) Vocalizations in Aptenodytes penguins: application of the two-voice theory. Auk 109:654-658

Rodary D, Bonneau W, Le Maho Y, Bost CA (2000a) Benthic diving in male emperor penguins Aptenodytes forsteri foraging in winter. Mar Ecol Prog Ser 207:171-181

Rodary D, Wienecke BC, Bost CA (2000b) Diving behaviour of Adélie penguins (Pygoscelis adeliae) at Dumont d'Urville, Antarctica: nocturnal patterns of diving and rapid adaptations to changes in sea-ice condition. Polar Biol 23: $113-120$

Ropert-Coudert Y, Kato A, Baudat J, Bost CA, Le Maho Y, Naito Y (2001) Feeding strategies of free-ranging Adélie penguins, Pygoscelis adeliae, analysed by multiple data recording. Polar Biol 24:460-466

Ropert-Coudert Y, Wilson RP, Daunt F, Kato A (2004) Patterns of energy acquisition by a central place forager: benefits of alternating short and long foraging trips. Behav Ecol 15: $824-830$

Ropert-Coudert Y, Kato A, Wilson RP (2006a) The Penguiness book. World Wide Web electronic publication (http:// polaris.nipr.ac.jp/ penguin/penguiness/), version 1.0, June 2006

Ropert-Coudert Y, Kato A, Wilson RP, Cannell B (2006b) Foraging strategies and prey encounter rate of free-ranging little penguins. Mar Biol 149:139-148

Sato K, Mitani Y, Cameron MF, Siniff DB, Naito Y (2003) Factors affecting stroking patterns and body angle in diving Weddell seals under natural conditions. J Exp Biol 206: 1461-1470

Schreer JF, Kovacs KM, O'Hara Hines RJ (2001) Comparative patterns of pinnipeds and seabirds. Ecol Monogr 71: $137-162$

> Shepard ELC, Wilson RP, Quintana F, Gómez Laich A, Forman D (2009) Pushed for time or saving on fuel: fine scale energy budgets shed light on currencies in a diving bird. Proc Biol Sci 276:3149-3155

Simeone A, Wilson RP (2003) In depth studies of Magellanic penguin (Spheniscus magellanicus) foraging: can we estimate prey consumption by perturbations in the dive profile? Mar Biol 143:825-831
Takahashi A, Watanuki Y, Sato K, Kato A, Arai N, Nishikawa J, Naito Y (2003) Parental foraging effort and offspring growth in Adélie penguins: Does working hard improve reproductive success? Funct Ecol 17:590-597

Weimerskirch H (1998) How can a pelagic seabird provision its chick when relying on a distant resource? Cyclic attendance, foraging decision and body condition in sooty shearwaters. J Anim Ecol 67:99-109

Wienecke B, Robertson GG, Kirkwood R, Lawton K (2007) Extreme dives by free-ranging emperor penguins. Polar Biol 30:133-142

Wilson RP (2003) Penguins predict their performance. Mar Ecol Prog Ser 249:305-310

Wilson RP, Peters G (1999) The foraging behaviour of chinstrap penguins Pygoscelis antarctica at Ardley Island, Antarctica. Mar Ornithol 27:69-79

Wilson RP, Wilson MP (1995) The foraging behaviour of the African penguin Spheniscus demersus. In: Dann P, Normann I, Reilly P (eds) The penguins. Surrea Beatty \& Sons, NSW, Australia, p 244-265

Wilson RP, Zimmer I (2004) Inspiration by Magellanic penguins: reduced swimming effort when under pressure. Mar Ecol Prog Ser 278:303-307

Wilson RP, Pütz K, Charrassin JB, Lage J (1995) Artifacts arising from sampling interval in dive depth studies of marine endotherms. Polar Biol 15:575-581

Wilson RP, Culik BM, Peters G, Bannasch R (1996) Diving behaviour of gentoo penguins, Pygoscelis papua: factors keeping dive profiles in shape. Mar Biol 126:153-162

- Wilson RP, Bost CA, Pütz K, Charrassin JB, Culik BM, Adelung D (1997a) Southern rockhopper penguin Eudyptes chrysocome chrysocome foraging at Possession Island. Polar Biol 17:323-329

Wilson RP, Pütz K, Peters G, Culik B, Scolaro JA, Charrassin JB, Ropert-Coudert Y (1997b) Long-term attachment of transmitting and recording devices to penguins and other seabirds. Wildl Soc Bull 25:101-106

Wilson RP, Ropert-Coudert Y, Kato A (2002) Rush and grab strategies in foraging marine endotherms: the case for haste in penguins. Anim Behav 63:85-95

Ydenberg RC (1988) Foraging by diving birds. Proc Inter Ornithol Congr XIX:1832-1842

> Ydenberg RC, Clark CW (1989) Aerobiosis and anaerobiosis during diving by western grebes: an optimal foraging approach. J Theor Biol 139:437-449

Zimmer I, Wilson RP, Gilbert C, Beaulieu M, Ancel A, Plötz J (2007) Foraging movements of emperor penguins at Pointe Géologie, Antarctica. Polar Biol 31:229-243

Proofs received from author(s): March 5, 2010 